Covered in: Web of Sciences (WOS); EBSCO; ERIH+; Google Scholar; Index Copernicus; Ideas RePeC; Econpapers; Socionet; CEEOL; Ulrich ProQuest; Cabell, Journalseek; Scipio; Philpapers; SHERPA/ROMEO repositories; KVK; WorldCat; CrossRef; CrossCheck

2018, Volume 9, Issue 1, pages: 165-181 | doi: https://doi.org/10.18662/po/11

\section{Education and Culture. Cultural \\ Consumption among Young People Aged 18-35}

\section{Gica PEHOIU ${ }^{1}$}

\author{
${ }^{1}$ Valahia University from \\ Targoviste, Romania, \\ gpehoiu@yahoo.com
}

\begin{abstract}
Background: Given the fact that the most important factors in developing a society are, inter alia, culture and education, we can say that in the social life of a community two factors determine the development of intellectual human capital potential in that community, transforming mentality, it creates the affirmation of cultural diversity and an open society aware of each member's value. Education and culture are, in fact, socially inclusive environments, which are the essence of national identity, being fundamental elements in interpersonal communication. Through education and culture are minimized differences between social groups and by this way can be highlighted the civilizing and manifestation degree of a nation or a people. The approach presented below is focused on analyzing infrastructure and consumption of cultural products by the youth, which is a set of behaviors that one person or several use cultural resources, such as listening to music, going to the opera, theater or cinema, visiting museums, watching programs with cultural destination, expressing interest in various types of cultural resources etc.
\end{abstract}

Keywords: education, culture, cultural infrastructure, cultural products consumption, youth.

How to cite: Pehoiu, G. (2018). Education and Culture. Cultural Consumption among Young People Aged 18-35. Postmodern Openings,
https://doi.org/10.18662/po/11 


\section{Introduction}

In the scientific literature, in multiple senses, the concept of „culture” is defined as a set of typical forms of life living of one or more members of a community, introspections on their self, nature and society that they belonging, in other words all spiritual attitudes. In another sense, „culture" expresses lifestyles customization and deployment of the existence of a group of people or their community, including its basic issues related to thinking, language, religious beliefs, behaviors, traditions, art, etc. (INCFC., 2013). Growth and diversification of supply and consumption of cultural values should be reconsidered as strategic objectives for the purposes of applying the policies and strategies for preserving and reviving the cultural phenomenon. In this regard, it is needed an integrated approach in which cultural infrastructure, production of cultural goods and services, education and training and policies on financial support of culture, as a whole, to be focused on the final issue, in this case the audience or consumer thereof, in all its forms. Under to the above mentioned cultural education, youth exhibit some cultural preferences personalized purchasing either from the education-school or favoring access to cultural sites, existing resources, related materials, opportunities for leisure in such locations, all of optimization effects for socialization and in terms of trends to individualize their own ways of relating with others. Among other things, sociology of culture, as one way of deepening the complex facets of the phenomenon to which we refer, deals with the concept of cultural consumption by associating it with the family and still their striking differences in social statuses. In this regard, there are a number of factors that influence cultural consumption behavior, among which can be mentioned:

- Lifestyle of a person, consumers of cultural products manifesting different traits, behaviors, motivations and attitudes, and regarding consumption and cultural development, organizations must identify and know their customers and their behavior;

- Economic factors affect the purchase decision process, particularly cultural product price and income available for the consumer;

- Interaction between consumer preferences and economic factors, growth and diversification of cultural consumption representing a composite endpoint based on marketing activities, education, and those regarding active participation (INCFC., 2013). 


\section{Research methodology}

Hypothesis: Consuming cultural products presents an overview of youth as an important part of completing the various lifestyles that it adopts in different moments of everyday life.

\section{Main objectives:}

- Identifying how students relate to cultural elements in family and public environments;

- Identifying the type of student behavior and preferences relating to infrastructure or cultural institutions of various profiles associated to cultural phenomenon;

- Quantification of consumption and participation in cultural events.

Methodology used is: bibliographical study, analyze and adapt the information from the literature to the present study, questionnaire-based survey, questionnaire development and implementation, statistical and mathematical processing of data, benchmarking, graphical representation.

The questionnaire of this study was applied to a sample of 276 students, aged 18-35 years, from Geography, History, Physical Education and Sports specializations of the Faculty of Humanities - University "Valahia" Târgovişte, Romania.

According to international studies, cultural indicators based on opinion surveys can be classified into several categories. In this sense, Derek Simons and Steven Dand (Derek Simons \& Steven R Dang, 2006)state:

- cultural indicators of environmental enhancement and regeneration of place, with regard to heritage conservation, improving the quality of the environment, reducing crime, social sustainability, reducing social disparities, jobs creation, economic growth;

- cultural indicators of individual wellbeing and personal development, which aim at measuring the frequency of interaction and participation in art and culture phenomena;

- cultural indicators of social capital and community building, which emphasize social cohesion within diversity and the contribution of arts and culture to social capital;

- cultural indicators of economic development, which envisage, among other things, the role of culture in the development of tourism industry or the role of art and culture in the knowledge economy;

- indicators of the cultural vitality of a community, which assess the contribution of arts and culture to the quality of life of a community; 
- indicators of the health and sustainability of the cultural sector, through which a distinction is made between different cultural sectors and those of a more pronounced economic nature (new media, advertising, entertainment, television, fashion, games, etc.).

It can also be said that there are opinion polls devoted to the cultural dimension that have been applied in the European space,("European Commission, Special Eurobarometer ", 2013) as follows: in the UK (Target Group Index) - on cultural consumption; Taking Part Survey - dedicated exclusively to cultural and sports consumption); in France (Les pratiques culturelles des français, applied exclusively to cultural consumption); Spain (Survey of Cultural Habits and Practices in Spain), also for cultural consumption; Norway (The Norwegian Cultural Barometer, dedicated to media consumption and culture).

At European Union level, culture issues are addressed in the special editions of the Eurobarometer survey, and since 2005, in Romania, the Barometer of Cultural Consumption is conducted annuall. (Training, 2015)

The main variables influencing the consumption of cultural products as, according to psycho-pedagogical studies respondents' age (with importance in terms of participation in cultural activities, we mention that most subjects were aged between 18 and 25 years); then a genital difference (females are more adaptable and respond promptly to requests); area of origin of the young people (urban / rural, more than half of them - 56\% coming from rural areas, the rest of them in urban areas); education level, and how leisure is manifested (it can be characterized as dependent on three main functions of individual, such as recreation, entertainment and personality development, the three components being found in close relation to each other; thus, by man rest mitigate his fatigue through entertainment eliminates boredom and personality development counterbalances the effects of automatism of thought used in everyday actions and in particular at work (Dumazedier \& Joffre, 1962-1971).

\section{Results and discusssions}

Analysis, processing and interpretation of the study's results presented highlights some general aspects of the issue reflected here, among which may be mentioned briefly:

- The results of the study participants were focused on issues concerning access to public cultural infrastructure or domestic one, renewable domestic consumer or public, and the frequency of their use, cultural consumption preferences, and individual values system; 
- Differences manifested in the cultural practices of young people, according to the environment in which they live (urban / rural);

- There were differences in terms of size of urban centers from where the students come (for example, between municipalities, county seat Târgovişte and Ploieşti - or Târgovişte and small towns such as Fieni, Titu, Găeşti, Câmpina, Câmpulung-Muscel, etc.);

- There are visible different cultural practices and behavior among students aged 18-25, compared to the ones with average ages of 26-35 years, even if their number and percentage are lower compared to the first category;

- Young people aged 18-25 face a number of problems related to the transition from compulsory education to active social life; separation from family; a new lifestyle and training; desire for financial independence; time accorded to cultural resource consumption; employment today. These are just some aspects that can be considered fluctuating in terms of cultural education. On the other hand, young people, given the social status held (the students) are more active through the party easiest leisure and environmental education that stimulates regarding socialization, so the strict relational local and the cultural especially through courses and seminars/practical work to which participate, supplemented with extracurricular activities;

- Young people aged 26-35 years are in transition to "second maturity", some of them engaging in the labor market and somewhat financially independent, are themselves consumers of cultural products, but they may have lack of free time to spend for such activities.

Responses to the questionnaire of participating subjects have highlighted the following aspects:

Regarding to the first question, concerning access to resources of domestic cultural infrastructure, the responses are shown in Fig. 1.

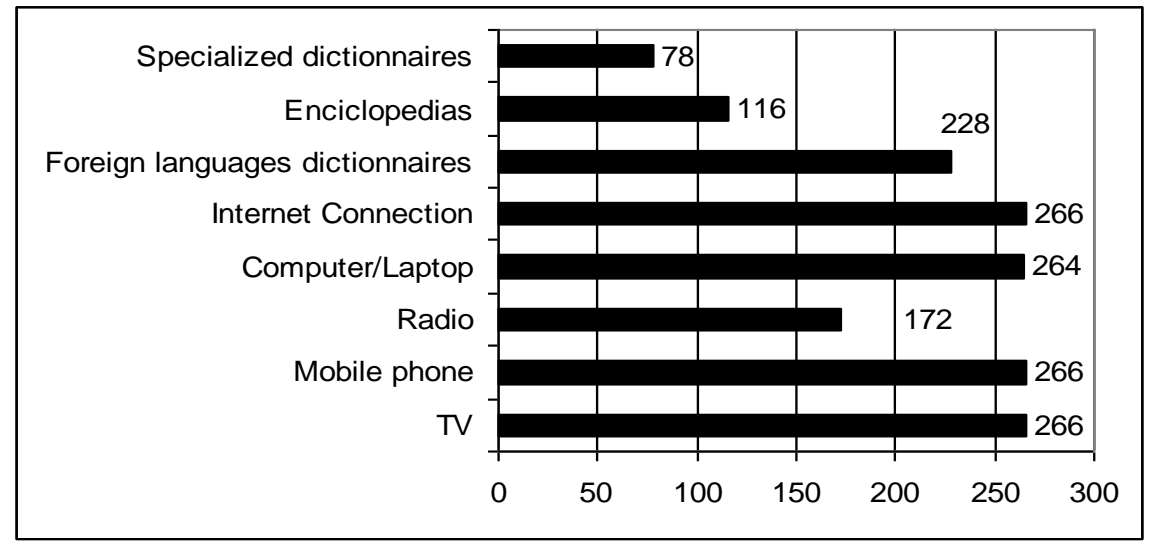

Fig. 1. Access to cultural domestic infrastructure. Do you have at home...? 
Answers to the first question allow us to find obvious manifestation influence of youth on dependence on mobile telephony, television, computer use and Internet $(98.3 \%$ of responses emphasizes access to infrastructure resources), on the one hand, and on the other hand, there is a visible decrease in using of specialized reference works (encyclopaedias, dictionaries, etc.). From here it can be considered a first conclusion: currently, students solve their professional training needs via the Internet or virtual / digital libraries sources. The question regarding access to written culture resources (excluding newspapers, magazines or specialized books) highlights, in turn, a relatively small share of the work held in personal library (Fig. 2), which confirms the above statement.

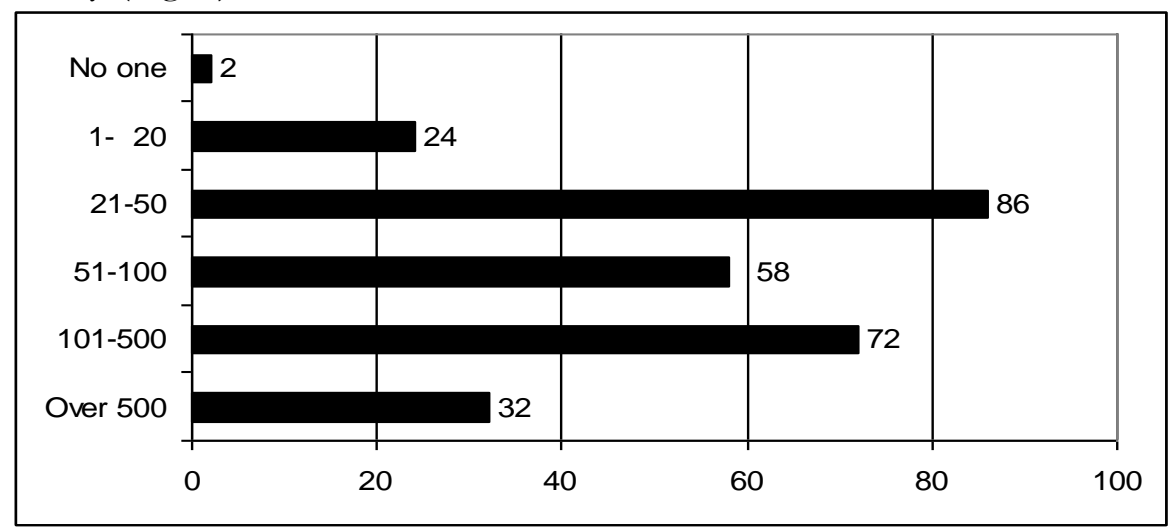

Fig. 2. Access to the cultural written resources: Excluding newspapers, reviews and school books, how many books do have at home?

The following questions refer to public cultural infrastructure, namely spaces for cultural activities where and in what place would be preferred by youth to be engaged in those activities (Fig. 3), subjects preferring as main location educational institutions in both responses, followed by the cultural institutions of the place of residence or where the subjects study, and places for entertainment (approx. 29\%). In this sense, we can say that cultural phenomena can not be dissociated from the objectives of spatial planning in that it is necessary to ensure accessibility to cultural institutions for all and also to satisfy the interests of various profiles, including support of infrastructure and the endowment equipment for participate to cultural practice. 


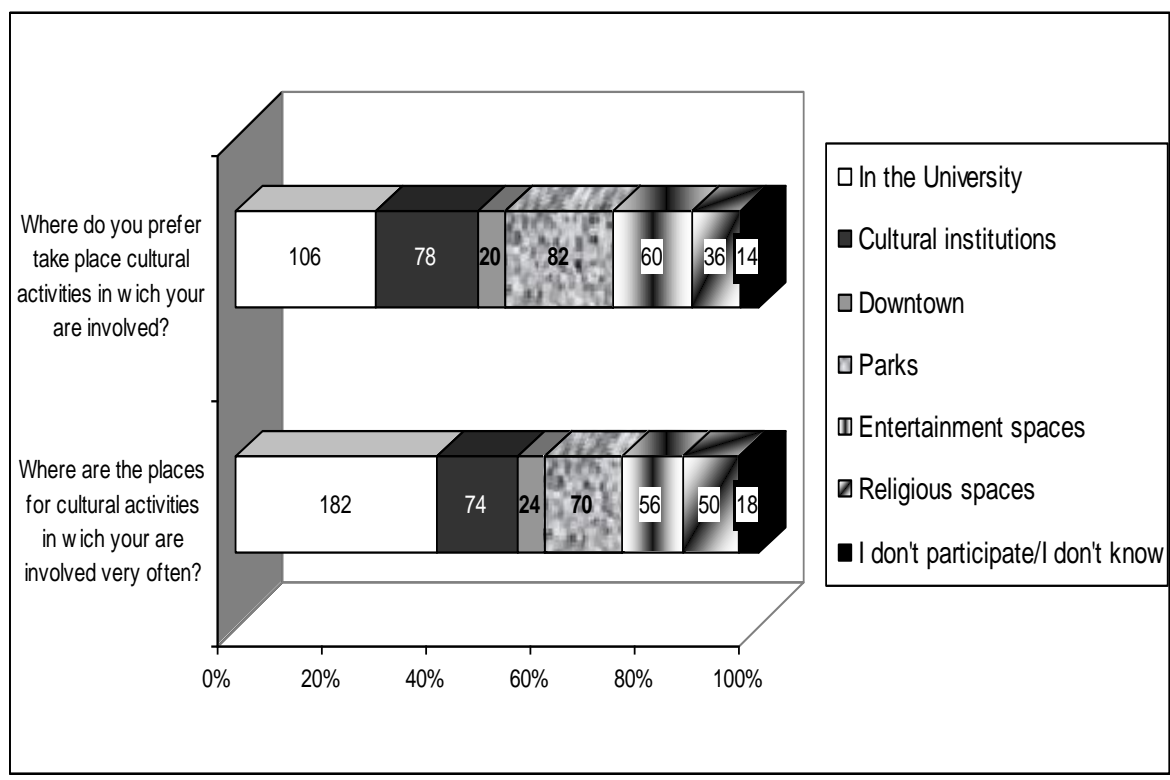

Fig. 3. Locations for cultural activities, depending on participation frequency and attractiveness

In terms of consumption of domestic cultural resources, most respondents revealed that they spend most of his free time (1-3 hours and more) each day watching movies and listening to music, watching TV programs or through other modern audio-video equipments like computers compatible with 3D, TVs and 3D visualization programs or devices, such as, among others, DVD players, tablets, smartphones, etc. (Fig. 4). One can say that through Internet applications can be found ways to download recent or older movies, music and not only such products. Movies on TV are not necessarily applied for the latest trends and the respondents show a preference to download movies from websites that host many such productions of various years and categorized by genres, both to satisfy their interest in the preferences, when their available time allows them to view them. 


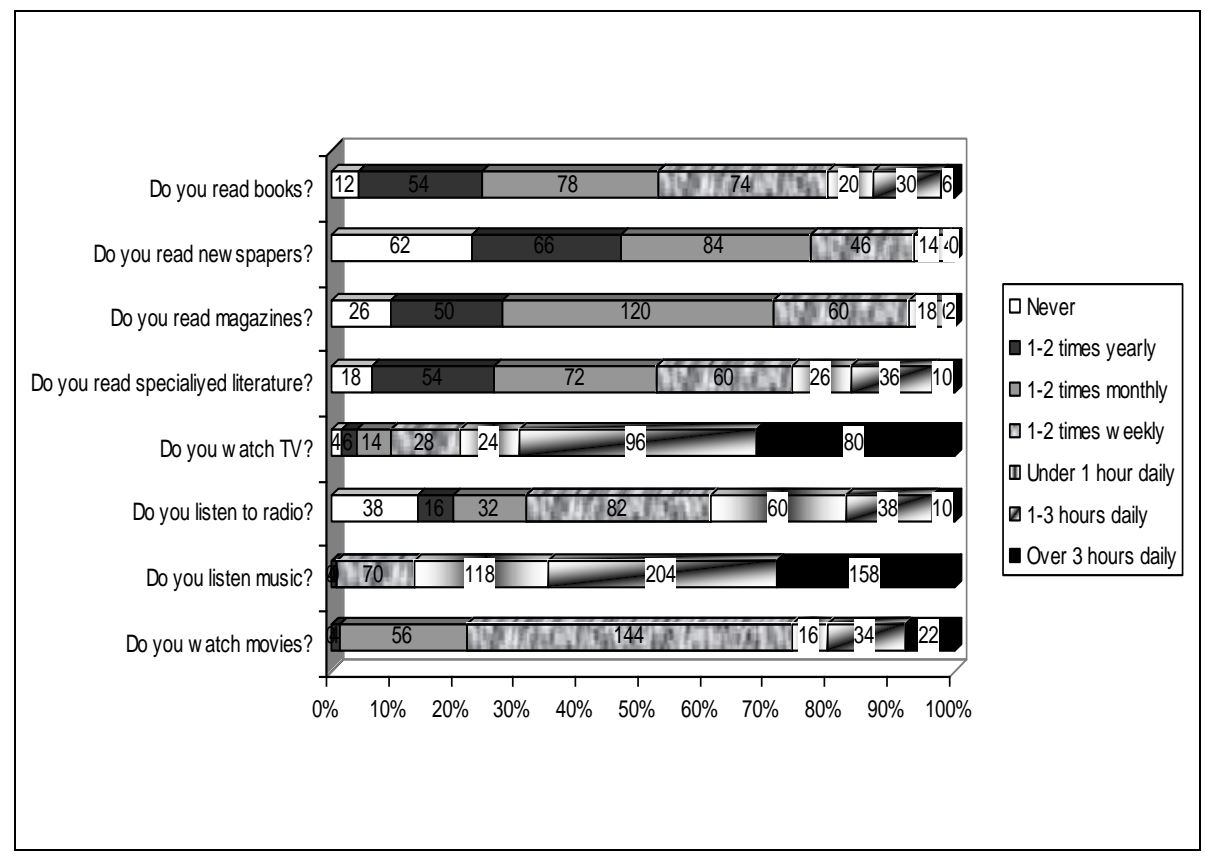

Fig. 4. Sources of domestic consuming and their usage frequency

Going to the cinema is an activity that is not of particular interest among contemporary youth, and a possible explanation could be that there are not anymore present operational locations and infrastructure for such type of cultural consumption, ie cinemas in operation in the localities from where students come and that situation is visible even in the municipality of Târgovişte, a town with medium size and population. Given the lack of these objectives or their reshaping, it was noticed lately appearance of several television channels that substitute social dimension and a movie viewing pleasure at the cinema. Considering these circumstances, it would be expected that, in the future, to be developed positive changes on cultural consumption like going to cinemas, if some locations that are under reconstruction will become functional again or others will be established later. Reading is a cultural practice that is rarely shown, which is performed most often annually, our study considering the statistics according to which $28 \%$ of respondents say they read a book once or twice monthly; instead newspapers and magazines are read monthly by more respondents $(30.4 \%$ respectively $43.4 \%$ ). These results indicate that periodicals will be part of people's preferences when they will be updated with the latest news in one area or another, whether they reading through the Internet or by consulting the printed formats. It is to be noticed that, however, the high percentage of 
young people that reads the literature, students reading increasingly more books, especially works of various specializations; the explanation can be seen on account of finding easily desired materials through online resources, fact that makes us to say that may be taken into account positive prospects for youth placement on a stable labor market. Moreover, it is noted particularly music listening, a majority of respondents $(74 \%)$ showing that they listen to music for $1-3$ hours daily and $57.2 \%$ more than 3 hours / day. In terms of active participation in cultural and creative activities, $76 \%$ of respondents say that they practice a hobby (singing, painting, writing, etc.), but only $45 \%$ express their artistic abilities month or several times a year (Fig. 5).

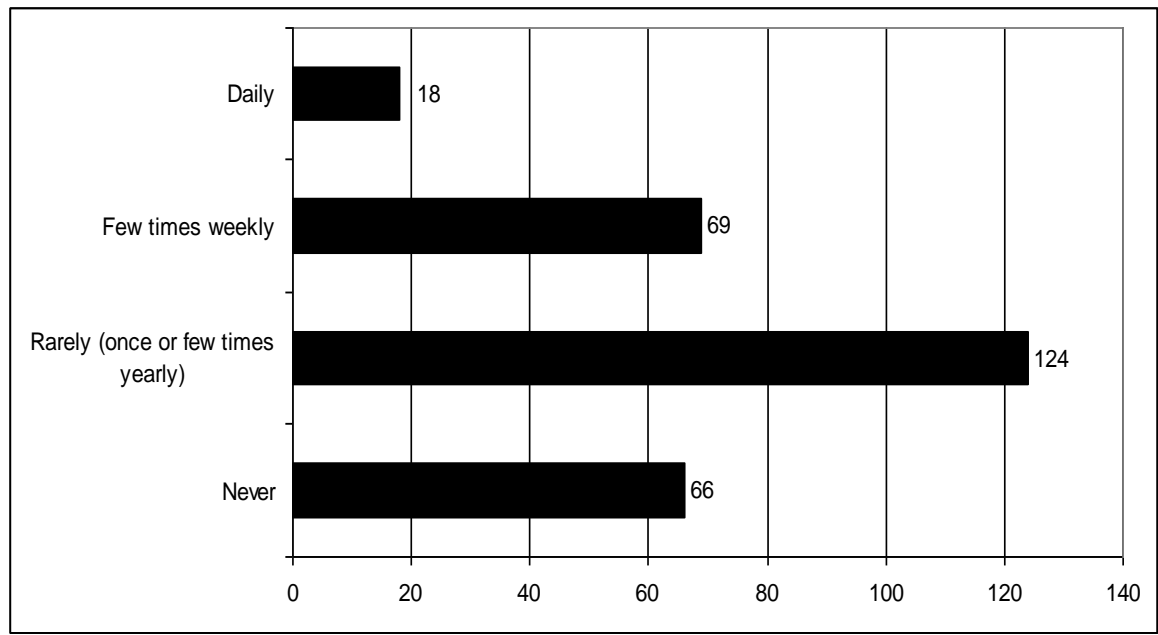

Fig. 5. Do you paint, write, sing?

Computer usage in the domestic space, both for professional and for entertainment (Fig. 6), highlights a number of responses, including:

- Young people use approx. 3 and even more hours during the day, in both cases by computer and the Internet, apps and programs for solving various professional situations; informing them of the scientific-pedagogical solving tasks, or necessary for solving in the classroom or in practical work and seminars from specialties in which they are enrolled; to watch and / or download some documentation contents of journals, articles, e-books, etc.;

- In a similar amount of time, most subjects use various IT applications for social networking and communication (ex.: Facebook, Linkedin, Twitter, Yahoo Messenger, etc.), for watching movies, listening to music tracks, for various games, to use e-mail, visiting the forums or blogs; 
- Young people is the age group that has the greatest degree of interest and the use of high technology, this facilitating their socialization with others.

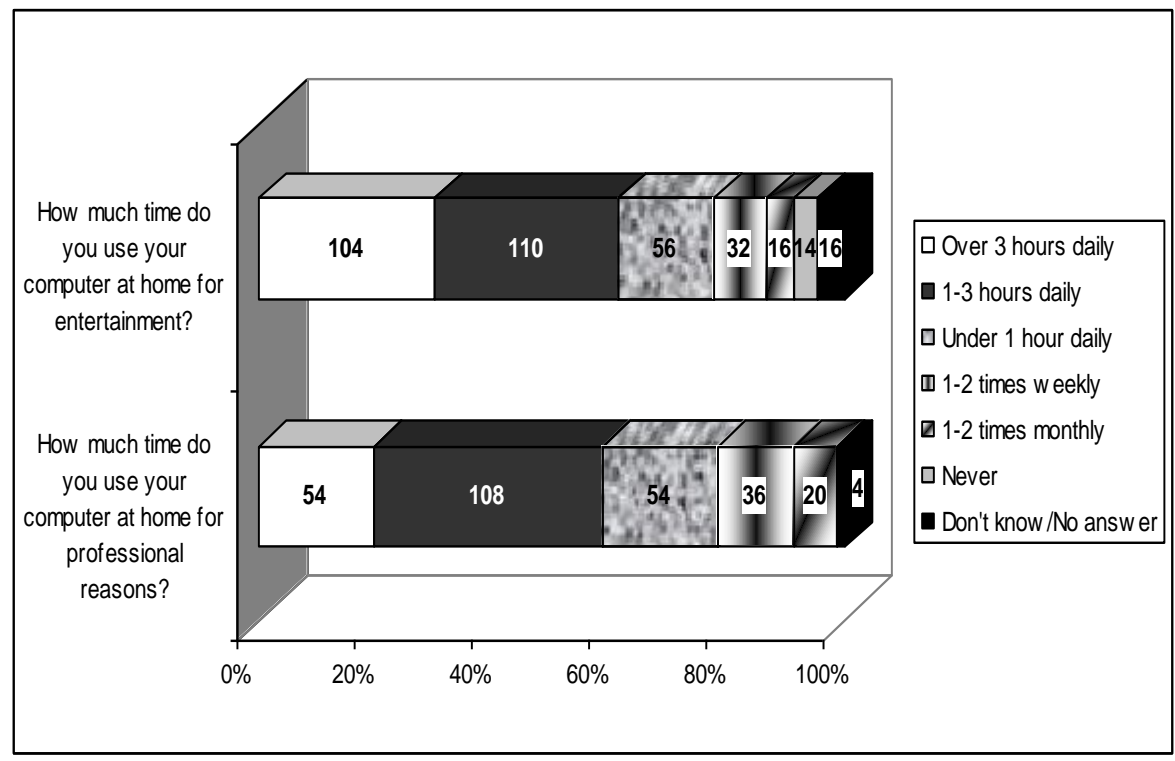

Fig. 6. Motivation and frequency of computer usage

Regarding public cultural infrastructure, ie spaces where cultural activities, by frequency of participation and attractiveness, it has low percentage of subjects participation, for example, only $12.3 \%$ of them preferring to go to the cinema several times a month, to visit museums and attend monthly theater having a percentage of only $6.5 \%$. Cultural consumption practiced at public events such entertainment knows better value segment represented by those who practice it a few times a month. Thus, $17.3 \%$ of respondents go a few times monthly at such events, and $66 \%$ rarely, about twice annually. Festivals dedicated to specific types of culture, national film festivals, music, theater, folklore, Romances National Festival "Golden Chrysanthemum", rock music concerts, pop / dance, jazz, etc., began to gather more and more young people by increasing interest in these forms of artistic expression and perception as common ways of leisure. Entertainment or music shows combine well with leisure activity spending time with friends or family. Their attractiveness can be explained by creating a festive atmosphere, focusing on specific genres, the relationship between the location and identity of that event, but also give opportunities of sharing experiences that participants have to the festival type. Cultural festivals 
generally are created to promote artists or genres, filmography, presentations of original creations or discovering new talents, but also to increase awareness and improve the image of an authority, a location or an institution. From these various reasons in recent years there was developed a large number of festivals, so that is why respondents receve a generous offer concerning these periodical events. Like the majority of types of public cultural consumption, people in rural areas are disadvantaged in terms of participation to cultural life and on receiving such resources. Very rarely or never expressed their willingness to participate at opera $(0 \%)$ or philharmonics $(8.6 \%)$, and these are only two examples. We are witness therefore to a low level of cultural consumption in the public space of nonconsumers of theater, opera, philharmonic etc. Some possible explanations are:

- Orientation of young people towards cultural consumption in the domestic space as a result of new technologies and media dissemination of cultural resources;

- Their orientation towards other forms of leisure; for example, going to shopping malls is preserved among their preferences regarding leisure (approx. 40\% of respondents indicated this option to go weekly to major shopping centers in large cities nearby respectively Bucharest and Ploiești);

- Walking in parks and green areas (31\%) is the most common leisure form, the highest percentages being registered for the category of weekly frequency;

- Monthly excursions outside of the locality is another way of leisure, quite common among people in general and youth in particular, almost $40 \%$ of respondents carrying out such activities at least once a month;

- $30 \%$ of respondents state they go a few times per month to clubs or church (Fig. 7-8). 


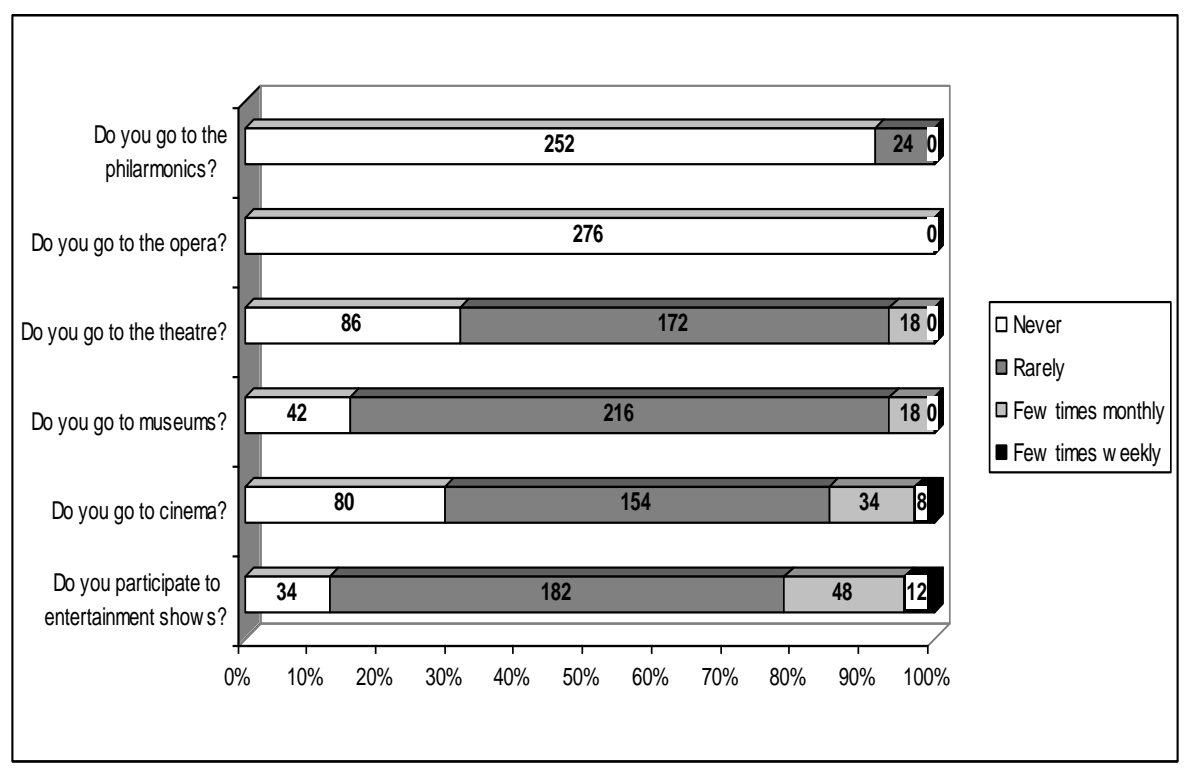

Fig. 7. Cultural public consumption and its frequency

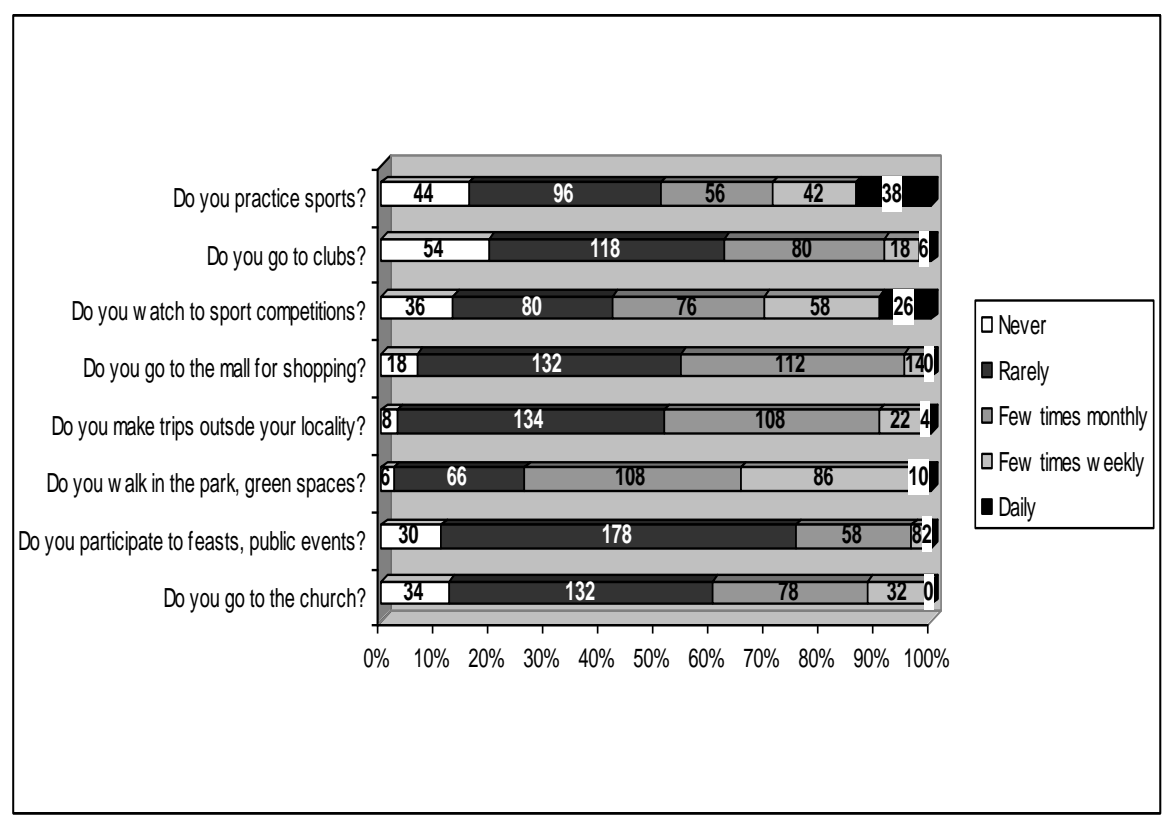

Fig. 8. Frequency of participation to some activities for free time

Holidays or local events can be considered to be the most accessible forms of public cultural consumption for those polled. To such events 
females participate in a greater number, urban environment being much better represented, but also rural areas being better represented than other forms of consumption. There is frequent participation in events celebrating the days of a city or a rural locality, etc. School's Day etc. Involvement in sports as a practitioner is highlighted particularly by students of Physical education and sports specialization, at the faculty mentioned above, and a smaller percentage, as a spectator, from other profiles. However, there are differences between the practices of leisure of youth by rural/urban, and the size of settlements from which respondents come. Decreasing youth participation on the frequency and consumption of public cultural resources can be explained by the fact that in some times of economic difficulties, people try predominantly to structure their costs, based on certain priorities, giving more importance to activities aimed to develop training or look for jobs. On the other hand, it can be observed that leisure activities with friends and family gained ground more than the expense of participation in various cultural performances, or are invoked as arguments the disinterest, lack of available time, limited offer of cultural products quality, lack of information on the organization and carrying out of such events, in fact, this being a situation found to the population of other EU countries (European Commission, „Special Eurobarometer 399. Cultural access and participation", Bruxelles, November 2013, p. 4-61). The last part of the questionnaire had questions focused on cultural consumption preferences of young people, ie music, film, and different levels of importance of values in their lives. In this context, favorite genres of young people are clearly defined in the following order: light music $(60 \%)$, followed by pop music $(40 \%)$ and a rate almost similar (34\%) as favorites folk music and manele, the last style being adopted as a national music gender (Fig. 10). Classical music and symphonic have a high level of non-participation (only 14\% prefer this kind) that is explained partly by the low percentage of young people who appreciate the genres, in other words, they are not included among musical preferences of this segment of the population. 


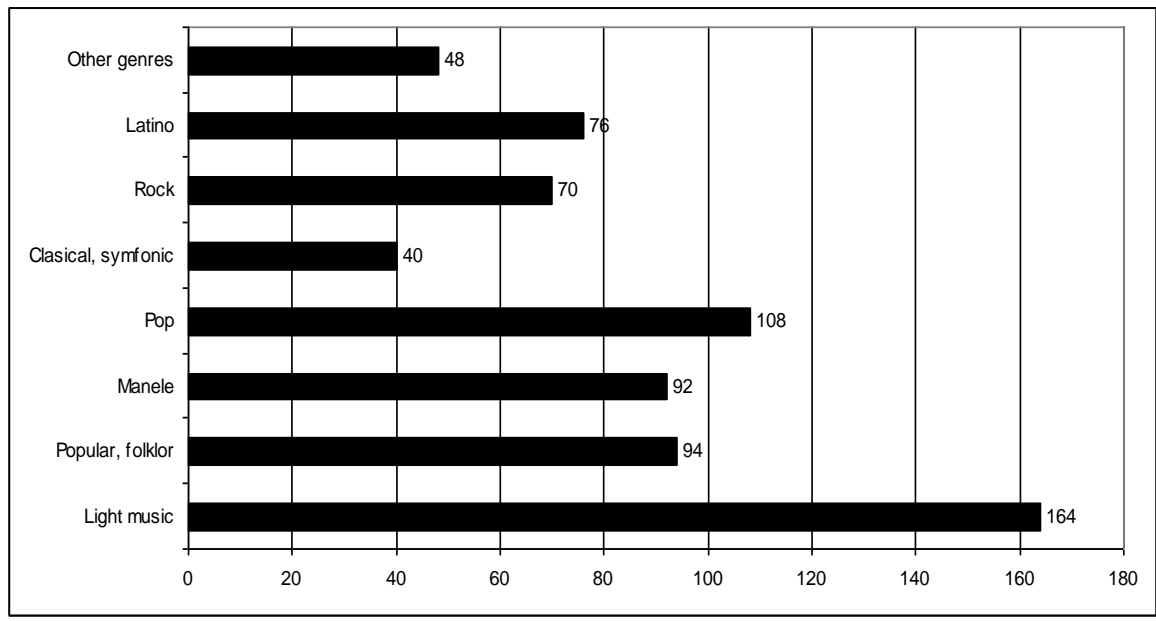

Fig. 10. What kind of music do you listen?

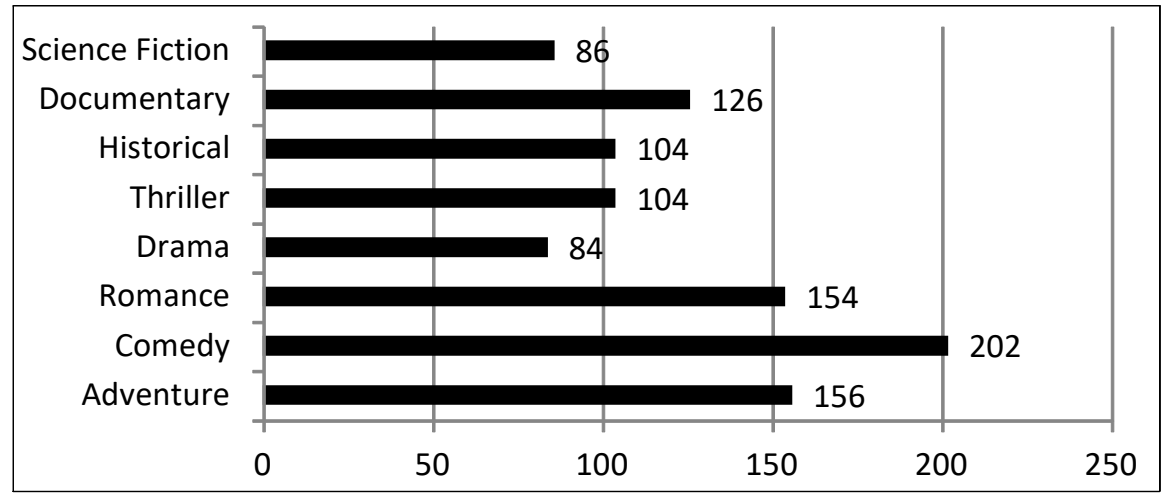

Fig. 11. What kind of films do you watch?

As seen in the above figure, comedies represent mainly young audience preference (approx. 73\%), followed by 156 responses in favor of adventure films (approx. 56.5\%) at a approximately equal distance regarding preferences for romantic movies (154 responses). However it is worth noting the diversity of preferences, no matter how popular they present in every film kind at youth. The last question of the survey was to determine the value system of the study subjects. Values of any person as part of behavior, decisions and attitudes, influence in general especially on how individual acts and, in particular, on the kind of choice for cultural activities. Values are express or implied conceptions, distinctive for each individual or a group, on what is desired, influencing selection procedures, ways and goals of any act 
available. One can speak, in this topic, about a so-called "value orientation" in terms of a conception organized and widespread, affecting behavior regarding the nature, the place owned by a human in his relations, his peers and desirable or undesirable ones, as they can be associated to environmental and human relationships. Besides, values do not show disparate but are part of a unified, designating an organization's longstanding beliefs about the existential goals and ways considered desirable to achieve them. Changing values, if that is necessary to produce or an individual assumes for himself, has affects in reordering priorities within the system of individual values. That is why the value system can be considered stable enough to reflect an individual's personality, and ability to relate to other value systems, especially cultural ones, of those around it. On determining the value system of the respondents were asked several questions about family, work, school, education, culture, leisure/relaxation, money, religion, friends, politics, using the question „How important is to you...?”, with the following gradual responses (Fig. 12).

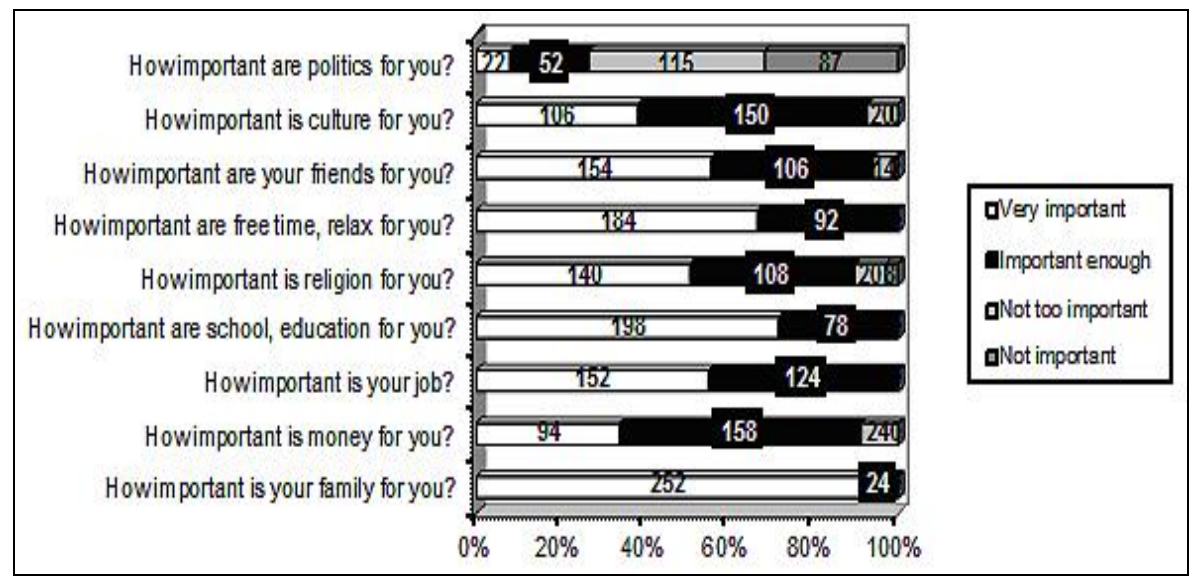

Fig. 12. Importance levels of the system of values

The answers highlight some key issues, including: over $90 \%$ of respondents say that family is very important, followed by school, education, leisure/ relaxation $(72 \%)$; similar values were found for responses to questions on work and friends (55\%); there is an interest of respondents for culture or religion; instead they are uninterested in politics in general.

\section{Conclusions}


A first conclusion resulting from this study is that the answers given by young people involved in this analysis clearly show an overview at a time, whereas all the problems relating to consumption of cultural products suffer a continuous transformation according to the four main variables presented in the working methodology of this paper. The second conclusion concerns the cultural consumption practices that are an important component of lifestyles that people, generally, and youth, particularly, adopt. Different lifestyles designate various forms and intensities of the cultural consumption. Among main elements of present analysis there are some aspects, and the following are more important:

- Area of residence and social-demographic characteristics are proving as important factors in the presence and access to cultural resources consumption, both domestic and public ones. In this sense, it can be advanced that the hypothesis of the paper, that covers cultural resources which determines their high levels of consumption, as achieved. The urban environment is a great consumer of culture, as having access to resources that favor its richer and varied offer of cultural and leisure activities. Instead, people in rural areas who have less access to these types of cultural resources, gives more importance to family, work, religion, material resources, and in terms of leisure forms it is manifested occasionally at local events, clubs, participation in entertainment or trips.

- Regarding the presence and access to domestic cultural infrastructure, it is found that there are many goods that fulfill multiple functions and compensate them on others. For example, mobile phones or smartphones can serve as cameras or camcorders as well as facilitating the access to the Internet. These electronic products, especially those with complex character, audio-video, facilitate users' access to cultural products and stimulate cultural consumption. The answers allow clear finding a preponderant influence of young people addicted to mobile telephony, television, computers and the Internet $(98.3 \%)$.

- In the domestic space, less highlighted is reading, a practice increasingly rare; there are, however, noteworthy responses about literature, students being concerned about their professional training, to affirm on the labor market. On the other hand, the lower positions are occupied by theatre plays, opera and philharmonics.

- At the same time, use of digital technology tends to replace the classic behaviors of cultural consumption - for example, reading printed books, reading them in electronic format, or replacing watching movies at the cinema with those which young people obtain through the Internet resources etc. If watching a movie was in the list of tasks to be assigned 
public consumption few years ago, today the same activity can be easily found in the list of activities for domestic consumption.

- Cultural consumption in public space, cultural shows have in turn other aspects such as youth favorite activities being mainly related to the participation to festivals and local events, to various sports events, entertainment, music concerts, etc.

- The consumption of cultural products in both domestic and public sectors was influenced by the economic and financial crisis lowering the possibilities of purchase or product new cultural infrastructure or other products, such as tickets access to various leisure activities, shows, concerts, visiting touristic objectives, etc.

Finally, we can say that the hypothesis and objectives of this study were fully confirmed and responses of participants to this lead us to say that youth are interested in cultural education and consumption of cultural resources specific to the current course in various degrees depending on the issues took into account.

\section{Acknowledgment}

This paper is the contribution of the author only and was not created with any other help of any institution or person.

\section{References}

Derek Simons, \& Steven R Dang. (2006). International perspectives on cultural indicators : a review and compilation of cultural indicators used in selected projects: University: Centre of Expertise on Culture and Communities. Dumazedier, \& Joffre. (1962-1971). Leisure, its functions and its socialeconomic status. In D. I. \& A. I. (Eds.), French contemporary sociology. Bucuresti: Editura Politica.

European Commission, Special Eurobarometer (2013).

INCFC. (2013). Sectoral Strategy in the Domain of Culture and National Heritage for 2014-2020. In. Bucharest

Training, N. I. f. R. a. C. (2015). Cultural Consumer Barometer, Culture between Global and Local. 